Discordia

\title{
Fons Meijer
}

\section{Verzoening en twist}

\section{De Nederlandse rampencultuur in de negentiende eeuw ideologiekritisch beschouwd ${ }^{1}$}

In de negentiende eeuw grepen vertegenwoordigers van de gevestigde orde rampen aan om nationale gemeenschapszin te propageren. In gedichten, gedenkboeken en prenten stelden zij de natie voor als een liefdevol huisgezin. We moeten echter oog hebben voor de sterke ideologische, veelal conservatieve implicaties van dit verzoeningsvertoog en de tegenreacties die het bij verschillende emancipatiebewegingen losmaakte.

In februari 1825 publiceerde de Engelse, in Amsterdam woonachtige predikant A.S. Thelwall het pamflet Keert $U$ tot Hem die slaat. Eene christelijke opwekking aan de Nederlanders. Aanleiding voor deze publicatie was een grootschalige watersnood die met name de kuststreken van Friesland, Overijssel, Gelderland en Noord-Holland zwaar had getroffen. ${ }^{2}$ Thelwall interpreteerde de ramp als een straf van God voor de zonden van de Nederlanders. Hij vond dat de bijzondere relatie tussen de Nederlanders en de 'Hemelsche Vader' al geruime tijd verstoord was. De omgang met rampen was wat Thelwall betreft symptomatisch: na rampspoed waren ze alleen nog maar bezig met liefdadigheid en niet meer met boetedoening. Enkel hernieuwde vroomheid zou er volgens Thelwall voor kunnen zorgen dat nieuwe rampen in de toekomst zouden uitblijven. Met dit standpunt vervreemde hij zich expliciet van het gros van de Nederlandse maatschappij, dat een veel milder godsbeeld had en juist veel belang hechtte aan liefdadigheid na grootschalige rampen.

Hoe moeten we dit provocerende pamflet begrijpen in de context van de negentiende-eeuwse Nederlandse rampencultuur? Veel onderzoekers van de negentiende eeuw menen dat rampen in deze periode aanjagers waren van sterke, regio-overstijgende solidariteitsgevoelens, die onder meer geuit werden middels grootschalige, nationale liefdadigheid. 
Letterkundige Marita Mathijsen benadrukt bijvoorbeeld het altruïstische karakter van dichters als Hendrik Tollens en Willem Bilderdijk, die hun proza en poëzie na rampen hebben ingezet om geld op te halen voor slachtoffers. Deze liefdadigheidsuitgaven getuigden van een sterke sociale bewogenheid bij deze schrijvers, aldus Mathijsen. ${ }^{3}$ De Duitse historicus Jürgen Osterhammel benadrukt dat dit een internationaal verschijnsel was. In zijn wereldgeschiedenis van de negentiende eeuw beschrijft hij de opkomst van het fenomeen van de 'nationale' ramp in landen binnen en buiten Europa, waarbij rampen aanleiding gaven tot het vertonen van nationale betrokkenheid bij hulpverlening en wederopbouw. ${ }^{4}$ Hoe moeten we een tegendraadse figuur als Thelwall, die liefdadigheid juist hekelde als een vorm van goddeloze ijdelheid, inpassen in het beeld van rampen als aanjagers van nationale naastenliefde en maatschappelijke betrokkenheid? Betrof hij slechts een 'uitzondering die de regel bevestigde' of was er sprake van een tegenbeweging?

In deze bijdrage wil ik een ander perspectief op de rampencultuur van de negentiende eeuw bieden. Ik zal laten zien dat de verzoenende en inclusieve houding die rampen losmaakten vaak sterke ideologische, veelal conservatieve implicaties had. Hierbij bouw ik voort op inzichten van literatuurwetenschapper Laurens Ham, die reeds stelde dat liefdadigheidsinitiatieven, en dan met name liefdadigheidspublicaties, niet alleen getuigden van een maatschappelijke bewogenheid, maar eveneens van een behoefte om de bestaande machtsverhoudingen te bestendigen. ${ }^{5}$ Ik zal laten zien dat het pamflet van Thelwall, ondanks de ultraorthodoxe standpunten, begrepen moet worden als een emancipatoire poging deze politieke implicaties te ondermijnen. Ook betoog ik dat deze strategie in de tweede helft van de negentiende eeuw navolging zou krijgen vanuit meer vooruitstrevende hoek.

\section{Consensuscultuur}

Negentiende-eeuwse rampen als stormvloeden, rivieroverstromingen en stadsbranden leidden vaak tot oproepen tot eensgezindheid en verzoening. Een vroege en prominente representant van deze reflex was Lodewijk Napoleon, de uit Frankrijk afkomstige koning van het Koninkrijk Holland (1806-1810). Tijdens verschillende rampen die het koninkrijk tijdens zijn korte regeerperiode teisterden, greep hij telkens naar taal en andere middelen om gemeenschapszin te versterken. Zo schreef hij landelijke 
collectes uit en riep hij Nederlanders vervolgens op om middels 'liefdegaven' (ofwel: donaties) medeleven te tonen voor 'hunner beklagenswaardige Landgenooten.' ${ }^{6}$ Bovendien bezocht hij rampgebieden en presenteerde hij zich telkens op messianistische wijze als de vader van de natie. ${ }^{7}$ In deze jaren werden de fundamenten gelegd voor een op nationaal niveau sterk op verzoening gerichte omgang met rampen, gekarakteriseerd door vorstelijke bemoeienis, de grootschalige organisatie van nationale liefdadigheid en de constructie van een nationale herinneringscultuur bestaande uit de toekenning van eretekens en de publicatie van gedenkboeken. ${ }^{8}$

Ham heeft opgemerkt dat publicaties van zogenaamde 'rampenauteurs' functioneerden als een belangrijke hoeksteen van deze consensuscultuur. Rampenauteurs waren vaak leden van de gevestigde orde en als ambtenaar, predikant of onderwijzer nauw betrokken bij de vormgeving van het publieke leven in Nederland. Geregeld brachten zij gedichten en verhalen op de markt om (een deel van) de opbrengst te doen toekomen aan de slachtoffers van een specifieke ramp. Deze teksten hadden een grote invloed op de manier waarop tijdgenoten de ramp maatschappelijk beleefden, aangezien dit soort drukwerk gretig aftrek vond en vaak werd voorgelezen in gezins- of verenigingsverband. De strekking van het gros van deze publicaties was dat rampen weliswaar verschrikkelijk en verwoestend waren, maar dat de natie juist in tijden van rampspoed samen wist te komen als liefdevol huisgezin. ${ }^{9}$ Zo beschreef Isaac van Haastert in een liefdadigheidsuitgave op poëtische wijze hoe Nederland na rivieroverstromingen in Gelderland in 1809 door alle samenwerking veranderde in een plek van deugd en vreugde:

Gezegend zijt ge o burgerschaar!

Gedrongen rondom 't deugd altaar,

Daar vorst en volk hun kracht vereenen

Zult gij met onweerstaanbren moed,

De Landen heffen uit den vloed,

En heil aanvoeren; na het wenen.

Zo worde d'akker van het verdriet

Herschapen in een oord van vreugde,

Zo zien wij in het naar verschiet,

Den dag des heils, tot neêrlandsch vreugde. ${ }^{10}$

Deze passage is eveneens exemplarisch voor de manier waarop rampenauteurs waarden als weldadigheid en opofferingsgezindheid vierden als onmisbare 


\section{Meijer}

bindmiddelen van het nationale gevoel en soms zelfs als typisch Nederlandse karaktertrekken.

Zoals Ham bovendien heeft opgemerkt, moeten we oppassen dat we een te rooskleurig beeld schetsen van deze consensuscultuur. Dergelijke publicaties waren niet enkel uitingen van een grote maatschappelijke betrokkenheid, maar vooral ook pogingen om de status-quo te bestendigen. ${ }^{11}$ Deze conservatieve tendens is echter een reactie op een universeel verschijnsel in moderne en complexe samenlevingen en volgens mij fundamenteler dan Ham doet vermoeden. Het is een bekend fenomeen dat the powers that be tijdens grote rampen bang is dat de sociale orde in het geding komt en hun status ondermijnd wordt. ${ }^{12}$ Deze angst is niet geheel onbegrijpelijk. Niet voor niets gebruikte een van de eerste rampensociologen de metafoor van 'gesmolten metaal' om samenlevingen in tijden van rampspoed en crisis mee te kwalificeren. ${ }^{13}$ Wat eerst rigide en statisch was, blijkt dan opeens veranderlijk en kneedbaar. Deze veranderlijkheid was vooral een beangstigend gegeven voor vertegenwoordigers van de gevestigde orde. Juist in de negentiende eeuw, een periode waarin maatschappelijke, politieke en culturele veranderingen zich in rap tempo en op grote schaal voordeden, bestond bij de gevestigde orde het sentiment dat rampen maatschappijontwrichtende gevolgen konden hebben. ${ }^{14}$

Rampenonderzoekers die kijken naar meer eigentijdse rampen wijzen erop dat deze paniek zich voornamelijk manifesteert in de vorm van repressie en machtsvertoon. Denk bijvoorbeeld aan de grootscheepse militaire inzet van de Amerikaanse overheid in de nasleep van orkaan Katrina in 2005. Ik zou echter willen betogen dat de gevestigde orde in Nederland van oudsher op een heel andere manier uiting gaf aan haar paniek: na rampen riepen schrijvers en predikanten veeleer op tot eendracht en pacificatie. Maatschappelijke onrust, protest of revolutie zouden alleen uitblijven als iedereen zich geborgen wist als onderdeel van de harmonieuze nationale gemeenschap, zo was de veelal onuitgesproken strekking van de consensusideologie. Middels publicaties na rampen bestendigden zij, bewust of onbewust, dit wereldbeeld. Hoewel de consensus-georiënteerde omgang met rampen op zijn massaalst was in de negentiende eeuw, mede door de inspanningen van koningen als Lodewijk Napoleon en auteurs van liefdadigheidsuitgaven, vinden we deze reactie op rampspoed eerder terug. Zo greep kunstenaar Romein de Hooghe in een bekende prent de Allerheiligenvloed van 1675 aan om te waarschuwen voor de gevaren van onderlinge verdeeldheid: tweedracht lag aan de basis van alle ramspoed en 
enkel eendracht zou voorkomen dat de Republiek ten onder zou gaan. ${ }^{15}$

Ik wil overigens allerminst beweren dat gemeenschapszin en barmhartigheid geen oprechte reacties op rampspoed waren. Na de meeste rampen manifesteerden medemenselijkheid en solidariteit zich in de vorm van reddingsacties en donaties en wisten gemeenschappen de gevaren gezamenlijk het hoofd te bieden. ${ }^{16}$ Solidariteit als praktijk en consensus als vertoog zijn dan ook twee fenomenen die weliswaar op elkaar in kunnen grijpen maar desondanks verschillend zijn.

\section{De conservatieve implicaties van consensuscultuur}

Dat de negentiende-eeuwse variant van de consensuscultuur bestaande maatschappijverhoudingen in de kaart speelde, blijkt in de eerste plaats uit de familiemetafoor die rampenauteurs veelvuldig toepasten in hun publicaties. Een ooggetuige schreef in een pamflet bijvoorbeeld op de volgende wijze over het bezoek van koning Willem III aan het door een overstroming getroffen Veenendaal in 1855:

Met vaderlijke genegenheid en op minzame wijze sprak Z. M. hen aan en vroeg hen of ze genegen waren om naar Utrecht te gaan, dat zij aldaar van spijs, kleederen, ligging en verwarming zouden voorzien worden, zij toonden zich hiertoe bereid, en gaven hoewel in boersche, toch in hartelijke bewoordingen hunne dankbaarheid aan hunnen geliefden Koning te kennen. ${ }^{17}$

De anonieme auteur benadrukt de hiërarchie tussen vorst en onderdanen door de inwoners van Veenendaal te karakteriseren als boers, nederig en dankbaar, en plaatst daar de minzame, genegen en vaderlijke vorstfiguur tegenover. Dit voorbeeld is illustratief voor de wijze waarop familiemetaforiek in publicaties van rampenauteurs conservatieve implicaties had. Binnen de voorstelling van de natie als huisgezin bleef er in theorie weinig tot geen ruimte over voor opstand tegen de koning, die als vaderfiguur als vanzelfsprekend een machtspositie bezat. Beter was het om de behaaglijkheid van het wijdverspreide huiselijkheidsideaal te erkennen, je terug te trekken in familie- en besloten verenigingsleven en te leven volgens de kwaliteiten van 'eenvoud, bezadigdheid, werkelijkheidszin, praktische vroomheid, deugdzaamheid en degelijke, kalme vaderlandsliefde. ${ }^{18}$ Wie toch oppositie voerde, ondermijnde de warmte en de harmonie van het nationale gezinsleven en liep de kans om door de autoriteiten als 'wederspannig kind' 
te worden gekwalificeerd - iets wat gebeurde toen er in het Zuiden op een gegeven moment onvrede over het bewind van Willem I ontstond. ${ }^{19}$

In rampenpublicaties kwam de verheerlijking van 'kalme vaderlandsliefde' vooral terug in de verbeelding van liefdadigheid als belangrijke uiting van patriottisme. Rampenauteurs verheerlijkten liefdadigheid als een van de voornaamste bronnen voor morele vooruitgang en een belangrijke exponent van deugdzaam nationaal burgerschap. Deze ideeënvorming leidde na rampen dikwijls tot drukwerkjes met titels als De weldadigheid (in 1809), Neêrlands milddadigheid (in 1820) en Opwekkingen tot weldadigheid (in 1825). Middels het geven van geld, het bezoeken van benefietactiviteiten, het schrijven van liefdadigheidsuitgaven en het fabriceren van hand- en kunstwerken voor verlotingen, nodigden auteurs lezers uit alle gelederen van de samenleving uit om te tonen dat ze het nationale ideaal een warm hart toedroegen. In een preek die tevens als liefdadigheidsuitgave op de markt gebracht werd, betoogde de Delftse predikant J. Scholten na een catastrofale stormvloed bijvoorbeeld dat alle Nederlanders met de ongelukkigen 'één groot huisgezin' vormden. Deze emotionele broederband moest middels liefdadigheid bevestigd worden: 'Dat gevoel van medelijden (...) moet bij den Nederlander, bij wien, in dit opzicht, gevoel en daad slechts één zijn, werkzaam, krachtig werkzaam worden, in het uitrijken van milde, aan de grootheid des ongeluks, en den dringenden nood geëvenredigde giften. ${ }^{20}$ Deze gedepolitiseerde opvatting van liefdadigheid als patriottisme moet vooral begrepen worden als een reactie op het gepolitiseerde en democratische burgerschapsideaal van de revolutionairen uit de achttiende eeuw. In wezen ontmoedigden auteurs als Scholten meer politieke vormen van burgerschap, zoals lid worden van een politieke groepering, en drukten zij de mogelijkheid tot opstand en activisme zo nog verder de kop in. ${ }^{21}$

Bovendien kende het liefdadigheidsvertoog na rampen een zeer exclusief karakter, iets wat Ham ook heeft benoemd. Het beoogde publiek voor liefdadigheidspublicaties betrof immers vooral de liefdadige burgers van de middenklasse: zij werden in de teksten aangesproken en 'geprezen om hun ruimhartigheid. ${ }^{22}$ Rampenauteurs voerden de vaak minderbedeelde slachtoffers in dit soort tekstjes echter slechts op als de passieve, lijdende voorwerpen, die weliswaar onderdeel waren van het nationale huisgezin, maar vooral dankbaar dienden te zijn voor de welwillendheid van anderen.

Ook bestendigde de verheerlijking van liefdadigheid de machtspositie van kerken. Bij de organisatie van armenzorg speelden kerkelijke organisaties in de negentiende eeuw nog een centrale rol. ${ }^{23}$ Hoewel deze inspanning 
theologisch gemotiveerd was - 'liefde' of caritas is een van de drie Bijbelse deugden en neemt als zodanig een centrale plek in binnen het denken over de relatie tussen God en de mens - hechtten de kerken echter ook om een andere reden aan hun actieve rol in de armenzorg. Liefdadigheid gaf ze de mogelijkheid middels het creëren van afhankelijkheidsrelaties het deel van de Nederlandse bevolking aan zich te binden dat in hun voortbestaan afhankelijk was van armenzorg. Dat auteurs liefdadigheid na rampen bejubelden als voorname nationale karaktertrek legitimeerde dus deze semi-particuliere organisatie van de armenzorg. Niet voor niets waren het vaak predikanten, publieke vertegenwoordigers van kerkelijke organisaties, die na rampen in hun preken de vruchten van liefdadigheid verheerlijkten.

\section{Betwiste consensus}

Terug nu naar A.S. Thelwall. Het pamflet dat hij in 1825 publiceerde, moet hoofdzakelijk worden gezien als verzet tegen de consensuscultuur die de omgang met rampen in Nederland toen al enkele decennia kenmerkte. Hij wees onder meer met een beschuldigende vinger naar de Nederlandse overheid, want zij had het nagelaten om na de stormvloed een zogenaamde bededag te organiseren. Bededagen werden van oudsher georganiseerd om collectief Gods genade te vragen, zo maakt ook Thelwall duidelijk: 'In vroeger tijd [konden] diergelijke [rampen] niet plaats hebben, of daar werd dadelijk een plegtige dag tot vasten en bidden afgezonderd, en uwe leeraren hadden u op alle predikstoelen ernstig opgewekt u zelven te verootmoedigen voor God in de belijdenis uwer zonden (...)'. Van een dergelijke vroomheid was nu weinig sprake meer, want 'thans [schijnt] men aan zulke openbare kenteekenen van zelfvernedering weinig te denken'. Nog schuldiger waren volgens Thelwall de predikanten, die hij 'moordenaren der ziel' noemde. Zij kenden hun plek niet meer binnen de door God gegeven orde, aangezien ze het nalieten 'de ernstige prediking van de Wet' ten gehore te brengen en toehoorders 'tot sidderen en beven te brengen, opdat zij vlieden van den toekomstige toorn. ${ }^{24}$ De hele omgang met rampen moest op zijn kop: geen ijdele liefdadigheid meer, maar vroomheid en boetedoening.

Door zich expliciet te richten tot de overheid en de predikanten, twee voorname vertegenwoordigers van de consensuscultuur, plaatste hij een radicaal-orthodox verhaal tegenover de behoudende consensusideologie. Zijn verhaal draaide niet om liefdadigheid, nationale gemeenschapszin en burgerlijke hiërarchie, maar om christelijke opwekking en de 


\section{Meijer}

allerindividueelste vroomheid. Hoewel velen de felheid van Thelwall verwierpen, ontstond er desondanks een welwillende coalitie van medeorthodoxen, onder wie dichter Willem Bilderdijk, die zich eerder juist nadrukkelijk met liefdadigheid had ingelaten. Deze orthodoxen zouden zich in de loop van de jaren twintig terugtrekken in een radicaal-orthodoxe tegenbeweging, Kerkhistorici hebben laten zien hoe de polemiek die na publicatie van het pamflet van Thelwall losbarstte als zodanig belangrijk is geweest in de ontstaansgeschiedenis van de Reveilbeweging. ${ }^{25}$ De felle kritiek op de burgerlijke consensusideologie had een grote invloed op het ontstaan van een tegencultuur die later nog zeer invloedrijk zou blijken in het Nederlandse publieke debat.

Dat een tegenreactie juist uit ultrabehoudende hoek kwam, is op zichzelf niet zo opmerkelijk. De consensusideologie stond met haar verheerlijking van gematigde vaderlandsliefde en hoop op morele vooruitgang immers met één been in de (christelijke) verlichting, een stroming waar de orthodoxe protestanten toch al weinig mee op hadden. Bovendien bestond er in Nederland al sinds de vroegmoderne tijd een rijke traditie van protestante orthodoxie. Ironisch genoeg zijn Thelwall en de zijnen voorlopers geweest van meer vooruitstrevende kritiek vanaf de tweede helft van de negentiende eeuw. Ook voor meer progressieve liberalen en socialisten zou de consensusideologie gaan functioneren als een belangrijke kopvan-jut. De liberalen stonden een transparante staatsinrichting voor en hadden door dat de voorstelling van de natie als liefdevol huisgezin nog te veel de ondoorzichtige, semiparticuliere machtsstructuren van het ancien regime legitimeerde. Iets soortgelijks gold voor de socialisten, al vormde hier de kritiek vooral dat de op consensus-georiënteerde publieke cultuur de arbeiders te veel afhield van een juist klassenbewustzijn en zo hun emancipatie in de weg stond.

$\mathrm{Na}$ twee grote rivieroverstromingen in Gelderland, in 1855 en 1861, kwam in de eerste plaats met name de liefdadigheidscultuur onder vuur te liggen. Na deze rampen was er een hausse aan liefdadigheidsinitiatieven, in de vorm van liefdadigheidsdrukwerk, benefietconcerten en verlotingen. Modernistische en liberale criticasters trokken de motieven van de aanjagers van deze liefdadigheid na rampen in twijfel en hekelden eveneens de esthetische kwaliteit van veel liefdadigheidsdrukwerk. ${ }^{26}$ Het hoogtepunt voor deze kritiek was 1861. Toen drukte De Nederlandsche Spectator verschillende spotprenten af waarin tekenaar J.M.S. Krans het potsierlijke karakter van verschillende aspecten van consensuscultuur benadrukte, zoals 
liefdadigheidsloterijen en het uitdelen van eretekens. ${ }^{27}$

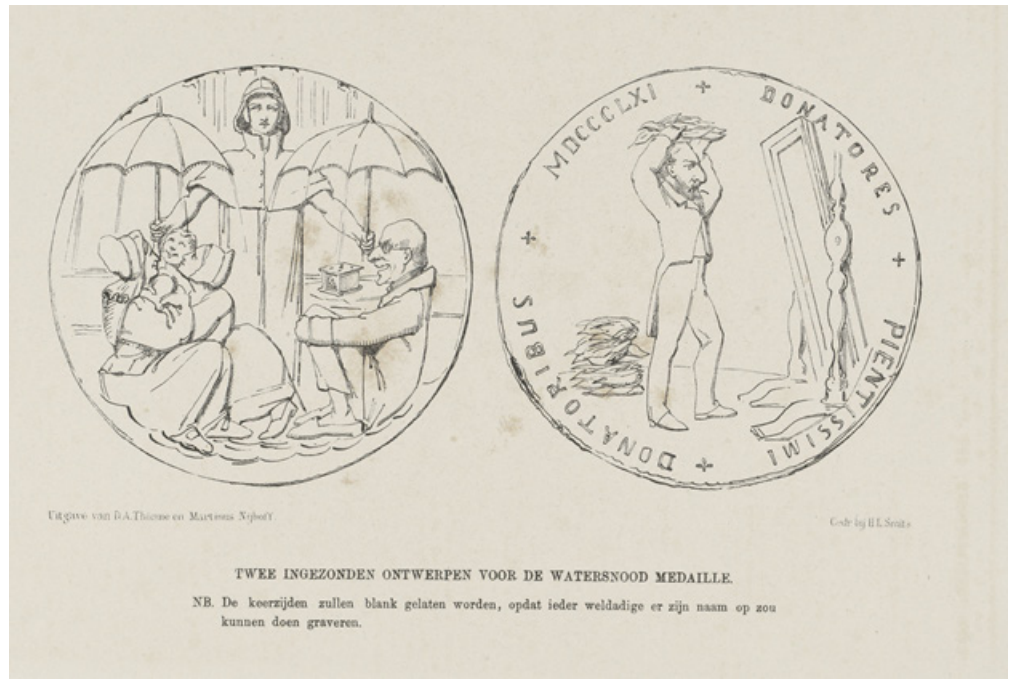

Afbeelding 1. Spotprent op de watersnoodsmedaillie die de overheid aan weldadige Nederlanders uitreikte. Deze verscheen op 6 april 1861 in de Nederlandsche Spectator. Bron: Rijksmuseum Amsterdam.

Nog feller was Multatuli: in een pamflet ageerde hij tegen de schijnheiligheid van veel Nederlanders, die enkele maanden na de grote liefdadigheidsacties hun hand nu op de knip hielden voor de slachtoffers van een watersnood in Nederlands-Indië. Multatuli hield de lezer in het pamflet als het ware een spiegel voor:

En zou het u niet smarten, wanneer de Javaan u verdacht van eigen baat, van huichelarij? Wanneer hij zeide: 'gij eischt de vruchten van mijnen arbeid, en gij beweert mij te beschaven, te veredelen. Gij neemt onze velden, en biedt daarvoor de boodschap aan dat wij broeders zijn, - welnu, de arbeid is volbragt, wij stonden u onze akkers af. - waar is uwe beschaving, waar is uw adel, waar is uwe broederschap? ${ }^{28}$

Terwijl de lezer een zelfgenoegzaam burgermansleven leidde, liet hij de Javanen aan hun lot over. Multatuli ontmantelde hier als het ware de dubbele moraal van het verzoeningsideaal: de Javaan hoorde alleen bij het nationale huisgezin als dit de christelijke Nederlander zo uitkwam. Het huiselijkheidvertoog werd in de koloniën alleen toegepast om hiërarchieën te creëren en te bestendigen, zo liet Multatuli zien. Van de zogenaamd 


\section{Meijer}

liefdadige inborst van de Nederlander, die auteurs zo vaak bezongen, bleek in de praktijk helemaal niets.

In de loop van de jaren tachtig sloten ten slotte ook socialisten zich aan bij het verzet tegen de consensusideologie. Zij richtten hun pijlen met name op de figuur van de koning. In het befaamde schotschrift Uit het leven van Koning Gorilla, van de socialistische broodschrijver Sicco Roorda van Eysinga, werd bijvoorbeeld de reputatie van koning Willem III als betrokken vadervorst in tijden van rampspoed onderuitgehaald:

De waarheid is echter dat hij bij dien watersnood geregeld dronken was en dan de alleronzinnigste dingen deed, zoodat men meer last dan plezier van hem had. Zoo wilde hij eens, toen hij een zwaar stuk in had, dwars over de rivier de [Waal] loopen, waarin hij natuurlijk zou zijn verzopen, als zijn adjudanten hem niet met kracht en geweld hadden tegengehouden. ${ }^{29}$

Het beeld dat de koning dronken door het rampgebied had gewaggeld, contrasteerde sterk met de gangbare beeldvorming. Willem III was, volgens de auteur, geen opofferingsgezinde vadervorst, nee, hij was een beschonken idioot. Het beeld van de vorst als liefdevolle vader vormde het hart van de consensuscultuur en het pamflet liet op polemische wijze zien dat van dit beeld niets klopte. De passage in Koning Gorilla vormde dus een breekijzer om de nog onverminderd aanwezige hiërarchische, paternalistische en consensus-georiënteerde beeldvorming rond vorst en natie open te breken. Later zou in linkse hoek overigens nog vaker naar spot en satire gegrepen worden om de consensusbeeldvorming rond vorstelijke bezoeken aan rampgebieden te ondermijnen. Zo schreef het Nijmeegse communistische vakbonds- en gemeenteraadslid Cees Hamet een spottend gedicht bij een bezoek van koningin Wilhelmina en haar man prins Hendrik na een watersnood in 1926. Vooral de prins komt er niet al te best vanaf: hij wordt opgedist als een luie donder die niet mee wil naar het rampgebied omdat het daar zo 'kalt oent ook nasz' is. Zijn protest bleek aan dovemansoren gericht.

Maar H.M. wou d'r niets van hooren en zei:

'Wij pakken ons lekker d'r in,

'Mijn over-groot-varkens-vader was Geus,

'En ik, Willemien, ben Geuzin!'30 
Dit gedicht illustreert hoe het Nederlandse rampendiscours, net als de gehele samenleving, tegen het begin van de twintigste eeuw meer gesegmenteerd raakte. Hoewel de Nederlandse rampencultuur nog steeds nationaliserende elementen bevatte, was er niet langer sprake van één, in de media overheersend discours dat de collectieve beleving van rampspoed bepaalde. Met de verzuiling, die het publieke leven in de eerste helft van de twintigste eeuw in toenemende mate zou gaan bepalen, verdween ook de consensusideologie als belangrijkste pijler onder de rampencultuur.

\section{Conclusie}

In deze bijdrage heb ik laten zien dat het beeld dat rampen in de negentiende eeuw vooral gemeenschapszin en altruïsme aanwakkerden te eenzijdig is. Om een volledig beeld te schetsen moet er eveneens aandacht zijn voor de conservatieve implicaties van het verzoeningsvertoog dat zoveel rampenauteurs bezigden. Wanneer we met een meer ideologiekritische blik naar dit vertoog kijken, zien we de pijlers voor een op nationale verzoening gerichte, maar tevens behoudende, paternalistische consensuscultuur. Zo bezien is het niet vreemd dat de consensuscultuur ook tegenreacties opriep vanuit gemarginaliseerde maatschappelijke groepen. Ik heb laten zien dat je deze polemieken kunt begrijpen als ideologische confrontaties. Het domein van de beeldvorming rondom rampen werd tijdens dit soort polemieken het domein van een emancipatiestrijd, eerst bij orthodoxe protestanten en later bij liberalen en socialisten. Dit deden zij door telkens representanten van de consensuscultuur te bekritiseren of te schofferen: de monarch, de overheid, predikanten, rampenauteurs en leden van de liefdadige middenklassen.

\section{Noten}

1. Deze bijdrage is tot stand gekomen binnen het NWO-Vici-project 'Dealing with Disasters in the Netherlands: The Shaping of Local and National Idenities, 1421-1890' (projectnummer 277-69-002) dat geleid wordt door prof. dr. Lotte Jensen en uitgevoerd wordt aan de Radboud Universiteit. Zie voor meer informatie: dealingwithdisasters.nl. Graag dank ik Lotte Jensen, Hanneke van Asperen, Adriaan Duiveman, Marieke van Egeraat en Lilian Nijhuis voor het commentaar dat zij op een eerdere versie van dit artikel hebben gegeven. 


\section{Meijer}

2. Frits David Zeiler, "1825: de 'vergeten' watersnood," Tijdschrift voor Waterstaatsgeschiedenis 16 (2007): 19-26.

3. Marita Mathijsen, De gemaskerde eeuw (Amsterdam: Querido, 2003), 220-22.

4. Jürgen Osterhammel, Die Verwandlung der Welt. Eine Geschichte des 19. Jahrhunderts (München: C.H. Beck, 2009), 295.

5. Deze inzichten heeft hij uitgewerkt in: Laurens Ham, "Verbroken familiebanden. Negentiende-eeuwse consensuscultuur in liefdadigheidsuitgaven rond 1861," Acta Universitatis Wratislaviensis, Neerlandica Wratislaviensia 20 (2011): 113-27; Laurens Ham, "Het gebod of het genot. Multatuli als liefdadigheidsschrijver," Multatuli Jaarboek 34, nr. 68 (2012): 4-19.

6. De woorden komen uit een brief van minister A.P. Twent die op instigatie van de koning werd gestuurd, zie: H. Ewijk, Geschiedkundig verslag der dijkbreuken en overstroomingen langs de rivieren in het koninkrijk Holland. Eerste deel (Amsterdam: Joh. Allart en Jac. Ruys, 1809), 268-69.

7. Lotte Jensen, "'See our Succumbing Fatherland, Overwhelmed by Disaster, Woe and Strife": Coping with Crisis during the Reign of Louis Bonaparte," Dutch Crossing: Journal of Low Countries Studies 40 (2016): 151-64.

8. Toon Bosch, "Natuur en cultuur: Modernisering van hulpverlening na catastrofale overstromingen in de Nederlandse Delta, 1740-1861," Tijdschrift voor Waterstaatsgeschiedenis 21 (2012): 39-47; Lotte Jensen, Wij tegen het water. Een eeuwenoude strijd (Nijmegen: Uitgeverij Vantilt, 2018).

9. $\operatorname{Ham}(2011), 117-18$.

10. Isaac van Haastert, De lof der weldadigheid, toegewijd aan mijne landgenoten, over hunne roemwaardige deelneming in het lot der ongelukkige inwoonders van de overstroomde landen, in den water-en ijsvloed van de maand januarij 1809, en historisch nabericht (Delft: J.J. Stuerman, 1809).

11. Ham (2012), 9-10.

12. Dit is een fenomeen dat rampenonderzoekers 'elitepaniek' noemen: Lee Clarke and Caron Chess, "Elites and Panic: More to Fear than Fear Itself," Social Forces 87, nr. 2 (2008): 993-1014.

13. Samuel Henry Prince, Catastrophe and Social Change: Based upon a Sociological Study of the Halifax Disaster (New York: De Gruyter, 1920), 19.

14. N.C.F. van Sas, De metamorfose van Nederland. Van oude orde naar moderniteit, 1750-1900 (Amsterdam: Amsterdam University Press, 2004).

15. Hanneke van Asperen, 'Disaster and Discord: Romeyn de Hooghe and the Dutch State of Ruination' (paper in voorbereiding).

16. Rebecca Solnit, A Paradise Built in Hell. The Extraordinary Communities That Arise in Disaster (New York: Viking Penguin, 2010).

17. B.S., Twee dagen in Veenendaal gedurende den watersnood in maart 1855 (Dordrecht: J.P. Revers, 1855), 11.

18. Remieg Aerts, De letterheren. Liberale cultuur in de negentiende eeuw: het tijdschrift De Gids (Amsterdam: Meulenhoff, 1997), 40. Zie ook: Remieg Aerts, "Het ingetogen vaderland: huiselijkheid, maatschappelijke orde en publieke ruimte," in Een nieuwe staat. Het begin van het Koninkrijk der Nederlanden, ed. Ido de Haan, Paul den Hoed, 


\section{Discordia}

and Henk te Velde (Amsterdam: Prometheus/Bert Bakker, 2014), 251-74.

19. Jeroen van Zanten, Schielijk, Winzucht, Zwaarhoofd en Bedaard. Politieke discussie en oppositievorming 1813-1840 (Amsterdam: Wereldbibliotheek, 2004), 50-51; E.J. Krol, De smaak der natie. Opvattingen over huiselijkheid in de Noord-Nederlandse poëzie van 1800 tot 1840 (Hilversum: Verloren, 1997); Ham (2011), 116.

20. W. Scholten, Leerrede naar aanleiding van Genesis VII: 19-21, ter aanbeveling van de ongelukkigen door den watersnood, gehouden op den 21sten februarij 1825 (Delft: P. de Groot, 1825), 21-22.

21. Zie bijvoorbeeld: S.R.E. Klein, Patriots republikanisme. Politieke cultuur in Nederland (1766-1787) (Amsterdam: 1995).

22. Ham (2012), 9.

23. Marco H.D. van Leeuwen, "Armenzorg en charitas, ca. 1800-2000. Een historische erfenis," in Nationaal goed: feiten en cijfers over onze samenleving (ca.) 1800-1999, ed. Ronald van der Bie and Pit Dehing (Amsterdam: Centraal Bureau voor de Statistiek, 1999), 159-76, 161-62.

24. A.S. Thelwall, Keert $U$ tot Hem die slaat, eene christelijke opwekking aan de Nederlanders bij gelegenheid van de tegenwoordige overstroomingen (Amsterdam: P. den Hengst en Zoon, 1825), 4.

25. A. Kagchelland and M. Kagchelland, Van dompers en verlichten. Een onderzoek naar de confrontatie tussen het vroege protestante Réveil en de Verlichting in Nederland (1815-1825) (Delft: Eburon, 2009), 589-668.

26. Ham (2011), 120-24.

27. Jensen, Wij tegen het water. Een eeuwenoude strijd, 40-43.

28. Multatuli, Wijs mij de plaats waar ik gezaaid heb! (Rotterdam: H. Nijgh, 1861), 36.

29. Uit het leven van koning Gorilla (z.l.: z.j.).

30. René van Hoften, Franc Janssen, and Wim Janssen, eds., Huus toe, lillekerd. Liedjes en verhalen uit en over Nijmegen (Nijmegen: Dwarsstap, 1980), 175-77. 